\title{
Impairment of Cerebral Autoregulation during Extracorporeal Membrane Oxygenation in Newborn Lambs
}

\author{
BILLIE LOU SHORT, L. KYLE WALKER, KAREN S. BENDER, AND RICHARD J. TRAYSTMAN \\ Department of Pediatrics, The George Washington University School of Medicine, Children's National Medical \\ Center, Washington, DC 20010 [B.L.S.], and Department of Anesthesiology and Critical Care Medicine, The \\ Johns Hopkins Medical Institutions, Baltimore, Maryland 21205 [L.K.W., K.S.B., R.J.T.]
}

\begin{abstract}
This study was designed to evaluate the effect of normothermic partial bypass, or venoarterial extracorporeal membrane oxygenation (ECMO), on cerebral autoregulation. Fourteen newborn lambs, 1-7 d of age, were randomized into two groups: control (ligation of right carotid artery and jugular vein without ECMO; $n=7$ ) and ECMO (ligation with placement on routine venoarterial ECMO at $120-150 \mathrm{~mL} / \mathrm{kg} / \mathrm{min} ; \boldsymbol{n}=7$ ). After $1 \mathrm{~h}$ of ECMO or stabilization in controls, cerebral autoregulation was evaluated by lowering cerebral perfusion pressure (CPP) by increasing intracranial pressure through infusion of artificial cerebrospinal fluid into the lateral ventricle. Four ranges of CPP were evaluated: 1) baseline, 2) 55-40, 3) 39-25, and 4) $<25 \mathrm{~mm} \mathrm{Hg}$. In ECMO animals, cerebral blood flow (CBF) decreased from baseline $(39 \pm 7 \mathrm{~mL} / 100$ $\mathrm{g} / \mathrm{min}$ ) to $23 \pm 7$ and $12 \pm 2$ at CPP of $39-25$ and $<25$ $\mathrm{mm} \mathrm{Hg}$. In the control group, $\mathrm{CBF}$ was unchanged from baseline $(48 \pm 11 \mathrm{~mL} / 100 \mathrm{~g} / \mathrm{min})$ until $\mathrm{CPP}$ was $<25 \mathrm{~mm}$ $\mathrm{Hg}$, at which time it decreased to $27 \pm 16 \mathrm{~mL} / 100 \mathrm{~g} / \mathrm{min}$. Cerebral oxygen consumption decreased from baseline (4.2 $\pm 1.1 \mathrm{~mL} / 100 \mathrm{~g} / \mathrm{min}$ ) to $4.0 \pm 0.7$ and $3.2 \pm 1.3 \mathrm{~mL} / 100$ $\mathrm{g} / \mathrm{min}$ at CPP of 39-25 and $<25 \mathrm{~mm} \mathrm{Hg}$, respectively, in the ECMO group. In the control group, cerebral oxygen consumption was unchanged from baseline $(4.2 \pm 1.1 \mathrm{~mL} /$ $100 \mathrm{~g} / \mathrm{min})$ until CPP was reduced to $<25 \mathrm{~mm} \mathrm{Hg}(3.2 \pm$ $1.3 \mathrm{~mL} / 100 \mathrm{~g} / \mathrm{min}$ ). When CBF autoregulation was altered, i.e. when total $\mathrm{CBF}$ decreased, right-left hemispheric $\mathrm{CBF}$ differences were noted in both groups. These findings show that venoarterial ECMO, at flow rates of $120-150 \mathrm{~mL} / \mathrm{kg}$ / min, alters cerebral autoregulation in healthy newborn lambs and that, if CBF is decreased by an increase in intracranial pressure, carotid artery ligation can result in lower CBF on the ipsilateral side. (Pediatr Res 33: 289294, 1993)
\end{abstract}

\section{Abbreviations}

CBF, cerebral blood flow

$\mathrm{CMRO}_{2}$, cerebral oxygen consumption

CPB, cardiopulmonary bypass

$\mathrm{CPP}$, cerebral perfusion pressure

CSF, cerebral spinal fluid

E, cerebral fractional oxygen extraction

ECMO, extracorporeal membrane oxygenation

ICP, intracranial pressure

MAP, mean arterial pressure

OT, cerebral oxygen transport

Received July 21, 1992; accepted October 30, 1992.

Correspondence and reprint requests: Billie Lou Short, M.D., Department of Neonatology, Children's National Medical Center, 111 Michigan Ave., N.W., Washington, DC 20010
$\mathrm{PaO}_{2}$, arterial oxygen pressure

$\mathrm{PaCO}_{2}$, arterial carbon dioxide pressure

Autoregulation of the cerebral circulation is an important homeostatic mechanism that maintains $\mathrm{CBF}$ over a wide range of CPP (1-3). The presence of cerebral autoregulation has been demonstrated in adult humans and in adult, newborn, and fetal animals (1-4). Systemic insults such as severe asphyxia, hypoxia, and hypercarbia can disrupt cerebral autoregulation leaving the cerebral microcirculation vulnerable to alterations in systemic blood pressure $(1,2,5)$. In this state, hypotension can result in ischemic cerebral damage, whereas hypertension can cause cerebral hyperemia and thus the risk for cerebral hemorrhage.

Therapies such as hypothermic CPB have been shown to impair cerebral autoregulation in some studies $(6,7)$ but not in others $(8,9)$. These contradictory findings are related to differing use of hypothermia and acid-base blood gas management during CPB (9). To date, no studies have evaluated the effect of normothermic partial CPB or ECMO on cerebral autoregulation. Because the major cause of death in the ECMO population is intracranial hemorrhage, a full understanding of the effect of ECMO on the cerebral circulation is indicated $(10,11)$. The present study was designed to assess the effect of venoarterial ECMO on cerebral autoregulation in the healthy newborn lamb (12).

\section{MATERIALS AND METHODS}

Subjects. Fourteen anesthetized lambs of mixed breed, 1-7 d of age, were used for the study.

Surgical procedures. Lambs were anesthetized with pentobarbital $(10-20 \mathrm{mg} / \mathrm{kg})$ before surgery and then maintained on a drip $(3 \mathrm{mg} / \mathrm{kg} / \mathrm{h})$ throughout the remainder of the study. Catheters were placed in the right femoral artery and vein for blood pressure monitoring, i.v. fluid, and medication administration. The microsphere reference catheter was placed in the left lingual artery for both groups, with the microsphere injection catheter placed in the left ventricle, verified by pressure wave forms, in the controls only. To gain access to the superior sagittal sinus, the skull was entered in the midline approximately $1 \mathrm{~cm}$ anterior to the lambda sutures. The sagittal sinus was identified, and the overlying dura was punctured with a 19-gauge needle. The catheter tip was placed proximal to the confluence of sinuses to obtain sagittal sinus blood for analysis of cerebral venous blood gases and pressure monitoring. The lateral ventricle was cannulated by drilling a hole through the skull about $5 \mathrm{~mm}$ lateral to the midline between coronal and lambda sutures. The ventricular catheter was advanced into the lateral ventricle with placement 
verified by the free flow of CSF. The site of placement of the ventricular catheter was alternated so that an equal number of right and left catheters were placed. A pressurized reservoir of artificial CSF was connected by a three-way stopcock to the ventricular catheter so that ICP could be raised by intraventricular infusion of CSF. The composition of artificial CSF (in $\mathrm{mM}$ ) was: $\mathrm{Na}^{+} 151, \mathrm{~K}^{+} 3, \mathrm{Ca}^{+2} 1.25, \mathrm{Mg}^{2+} 0.6, \mathrm{Cl}^{-} 134, \mathrm{HCO}_{3-} 25$, and urea 6 . These concentrations are similar to those measured in lamb CSF (13). In control animals, the right jugular vein and carotid artery were isolated and ligated. In ECMO animals, the jugular vein catheter (14 French ECMO Venous Cannulae, Biomedicus Inc., Minneapolis, MN) was placed and advanced into the right atrium; the right carotid artery catheter (8-10 French, ECMO Arterial Cannulae, Biomedicus Inc.) was placed $3 \mathrm{~cm}$ above the aortic valve. This position was verified by pressure wave changes. All animals were systemically heparinized with 200 units/ $\mathrm{kg}$ of heparin, followed by a heparin drip of 50-75 units $/ \mathrm{kg} / \mathrm{h}$ to maintain an activated clotting time of 200-250 s.

$E C M O$ procedure. Venoarterial ECMO, as described before (12), was used for the study with the circuit consisting of the venous catheter, standard $1 / 4 \times 1 / 4$ inch polyvinyl chloride tubing, a 50-mL venous reservoir (R50, SciMed, Life Systems, Inc., Minneapolis, MN), a roller occlusion pump (Picker International, Mayfield Village, $\mathrm{OH}$ ), a $0.8 \mathrm{~m}^{2}$ SciMed membrane lung, a heat exchanger (P-7-14, SciMed), and the return arterial catheter. A flow of $120-150 \mathrm{~mL} / \mathrm{kg} / \mathrm{min}$ was used for the study.

Experimental protocol. After surgery, the animals were given pancuronium bromide $(0.1 \mathrm{mg} / \mathrm{kg})$ and pentobarbital $(3 \mathrm{mg} / \mathrm{kg} /$ h) and were maintained on a constant infusion of $10 \%$ dextrose, $0.45 \%$ saline at $20-25 \mathrm{~mL} / \mathrm{kg} / \mathrm{h}$. End-tidal $\mathrm{CO}_{2}$ was monitored, and ventilation was adjusted to maintain $\mathrm{PaCO}_{2}$ at approximately 4-7 kPa. $\mathrm{PaO}_{2}$ was maintained at $13.3-26.7 \mathrm{kPa}$ throughout the study period. Temperature was monitored and maintained at 39 $\pm 0.5^{\circ} \mathrm{C}$.

After a 1-h stabilization period, animals were divided into two groups for the study: control animals $(n=7)$ with carotid artery and jugular vein ligation only, followed by a 1 -h stabilization period after ligation (without ECMO); and ECMO animals ( $n=$ 7) placed on ECMO at 120 to $150 \mathrm{~mL} / \mathrm{kg} / \mathrm{min}$ for $1 \mathrm{~h}$ of stabilization. ECMO animals remained on ECMO during the autoregulation study period. In both groups, cerebral autoregulation was evaluated by increasing ICP and lowering CPP to achieve four ranges of CPP [CPP $=\mathrm{MAP}(\mathrm{mm} \mathrm{Hg})-\mathrm{ICP}]: 1)$ baseline $(>50), 2$ ) 55-40,3) 39-25, and 4) $<25 \mathrm{~mm} \mathrm{Hg}$. In each study group, ICP was increased over a 3- to 4-min period to achieve the desired level. Each ICP level was maintained for 5 min before studies were done. After the study, animals were euthanized with a pentobarbital overdose and $\mathrm{KCl}$ injection.

Physiologic measurements. CBF was measured by the radiolabeled microsphere technique (14). Radioactive microspheres of $15 \pm 1.0 \mu \mathrm{M}$ diameter (approximately $1.4 \times 10^{8}$ microspheres) labeled with ${ }^{153} \mathrm{Gd},{ }^{114} \mathrm{In},{ }^{113} \mathrm{Sn},{ }^{103} \mathrm{Ru},{ }^{95} \mathrm{Nb}$, and ${ }^{46} \mathrm{Sc}$ (New England Nuclear-Dupont Products, Boston, MA) were randomly chosen and $0.5 \mathrm{~mL}$ were injected over $45 \mathrm{~s}$ into the left ventricular catheter in the controls and into the arterial return catheter in ECMO animals. Previous studies have validated the injection of microspheres into the arterial catheter in ECMO animals (12). Ten $\mathrm{s}$ before the injection, a reference blood sample withdrawal was started from the lingual artery at a rate of $2.47 \mathrm{~mL} / \mathrm{min}$ with a calibrated syringe pump (Harvard Apparatus, Dover, MA), and was continued for $60 \mathrm{~s}$ after the injection was complete. Tissue and reference blood samples were counted in a deep-well gamma scintillation counter (Packard Multichannel Autogamma Scintillation Spectrometer, model 9042, Packard Instrument Co., Inc., Downers Grove, IL). Blood flow was calculated as the product of tissue counts times the reference withdrawal rate divided by the counts in the reference blood sample. Flows were normalized to $100 \mathrm{~g}$ of tissue weight. Blood flows were determined for total cerebrum, right and left cerebral hemispheres, brainstem, caudate, cerebellum, and areas of flow for the middle cerebral artery, posterior cerebral artery, anterior cerebral artery, and watershed area for the posterior-middle cerebral artery. All reference blood and tissue samples contained more than 400 microspheres.

Heart rate, MAP, ICP, CPP, arterial and venous $\mathrm{pH}, \mathrm{PCO}_{2}$, $\mathrm{PO}_{2}, \mathrm{Hb}$ oxygen saturation, and $\mathrm{Hb}$ were measured at each study period. Samples for $\mathrm{Hb}$ oxygen saturation and $\mathrm{Hb}$ were taken immediately before the injection of the microspheres. Measurements were made using the Hemoximeter OSM2 (Radiometer, Cleveland, $\mathrm{OH}$ ) calibrated for lamb's blood. $\mathrm{PO}_{2}, \mathrm{PCO}_{2}$, and $\mathrm{pH}$ were measured at $39.5^{\circ} \mathrm{C}$ using the Radiometer ABL 30. Blood pressure, sagittal sinus pressure, and ICP were continuously monitored (Gould Instruments, Ormand, CA).

Calculated values and data analysis. $\mathrm{CMRO}_{2}$ was calculated by multiplying blood flow to hemispheres by the cerebral arteriovenous oxygen content difference $\left[\mathrm{CMRO}_{2}=\mathrm{CBF} \times\right.$ (cerebral arterial oxygen content - cerebral venous oxygen content)]. OT was calculated as the product of $\mathrm{CBF}$ times arterial oxygen content. $\mathrm{E}$ was calculated as the ratio of $\mathrm{CMRO}_{2}$ to OT. Differences within group study variables were analyzed using repeated measures analysis of variance, with statistical significance defined as $p<0.05$. Post hoc analysis of the significant differences was conducted using the Newman-Keuls test to determine points of significance. Between-group differences were determined using the two-tailed $t$ test for independent variables with significance defined as $p<0.05$.

\section{RESULTS}

The average weight (ECMO $4.3 \pm 1$, control $4.8 \pm 1.5 \mathrm{~kg}$ ) and age (ECMO $4.3 \pm 1.6$, control $4.4 \pm 2.1 \mathrm{~d}$ ) of the two groups did not vary significantly.

Physiologic variables are shown in Table 1. There were no changes in heart rate, $\mathrm{MAP}, \mathrm{pH}, \mathrm{PaCO}_{2}, \mathrm{PaO}_{2}$, arterial oxygen saturation, or pulse pressure over the study period in either group. ICP was increased over the study period to achieve the appropriate CPP in both groups. There were no differences in heart rate, $\mathrm{pH}, \mathrm{PaCO}_{2}$, arterial oxygen saturation, pulse pressure, $\mathrm{CPP}$, or ICP between study groups. $\mathrm{PaO}_{2}$ was significantly higher in the ECMO group due to the efficiency of the membrane lung $(p=0.05)$. MAP was lower in the ECMO animals at baseline ( $69 \pm 19$ versus $88 \pm 19 \mathrm{~mm} \mathrm{Hg} ; p=0.04$ ). Because there were no differences between groups in CBF or $\mathrm{CMRO}_{2}$ at these points, these differences are probably of little or no physiologic significance.

Cerebral autoregulatory curves for control and ECMO animals are shown in Figures 1 and 2. CBF decreased from baseline at CPP of 39-25 and $<25 \mathrm{~mm} \mathrm{Hg}$ in ECMO animals $(p<0.001)$ (Table 2). In controls, CBF decreased only at a CPP $<25 \mathrm{~mm}$ $\mathrm{Hg}(p<0.03)$. CBF was lower at CPP of $39-25$ and $<25 \mathrm{~mm}$ $\mathrm{Hg}$ in the ECMO animals when compared with controls $(p<$ $0.03)$

Cerebral metabolism measurements are shown in Table 3 for control and ECMO animals. OT decreased in the ECMO animals at CPP of 39-25 and $<25 \mathrm{~mm} \mathrm{Hg}$ when compared with baseline $(p<.001)$ and in the controls at a CPP of $<25 \mathrm{~mm} \mathrm{Hg}(p=$ 0.04 ). OT was different between the ECMO and control groups at CPP of 55-40,39-25, and $<25 \mathrm{~mm} \mathrm{Hg}(p<0.03)$. Compared with baseline values, $\mathrm{CMRO}_{2}$ was lower in the ECMO animals at CPP of $39-25$ and $<25 \mathrm{~mm} \mathrm{Hg}(p=0.0002)$, and in the control animals at a CPP $<25 \mathrm{~mm} \mathrm{Hg}$, i.e. the point when autoregulation was lost in both groups. $\mathrm{CMRO}_{2}$ in the ECMO animals was lower than that of the control animals at CPP of $39-25$ and $<25 \mathrm{~mm} \mathrm{Hg}(p<0.02)$. E did not change in the ECMO animals, but it increased at a CPP of $<25 \mathrm{~mm} \mathrm{Hg}$ in the control animals $(p=0.03)$.

The right to left cerebral hemisphere differences in the ECMO animals are shown in Figure 3. Although both hemispheres were different from baseline at CPP of 39-25 and $<25 \mathrm{~mm} \mathrm{Hg}$, the right cerebral hemisphere showed a lower CBF than the left at 
Table 1. Cardiovascular and blood gas values in ECMO and control animals as cerebral perfusion pressure was decreased*

\begin{tabular}{|c|c|c|c|c|}
\hline & Baseline & CPP $55-40 \mathrm{~mm} \mathrm{Hg}$ & CPP $39-25 \mathrm{~mm} \mathrm{Hg}$ & $\mathrm{CPP}<25 \mathrm{~mm} \mathrm{Hg}$ \\
\hline \multicolumn{5}{|c|}{ Heart rate (bpm) } \\
\hline ECMO & $225 \pm 32$ & $229 \pm 41$ & $209 \pm 49$ & $214 \pm 34$ \\
\hline Control & $237 \pm 60$ & $224 \pm 66$ & $234 \pm 62$ & $219 \pm 66$ \\
\hline \multicolumn{5}{|c|}{ Pulse pressure $(\mathrm{mm} \mathrm{Hg})$} \\
\hline ECMO & $32 \pm 13$ & $32 \pm 15$ & $29 \pm 10$ & $36 \pm 10$ \\
\hline Control & $39 \pm 7$ & $36 \pm 5$ & $36 \pm 8$ & $40 \pm 9$ \\
\hline \multicolumn{5}{|c|}{$\mathrm{MAP}(\mathrm{mm} \mathrm{Hg})$} \\
\hline ECMO & $69 \pm 19 \dagger$ & $72 \pm 23$ & $71 \pm 19$ & $77 \pm 16$ \\
\hline Control & $88 \pm 12$ & $82 \pm 15$ & $78 \pm 17$ & $79 \pm 15$ \\
\hline \multicolumn{5}{|c|}{$\mathrm{ICP}(\mathrm{mm} \mathrm{Hg})$} \\
\hline ECMO & $4 \pm 3$ & $27 \pm 34$ & $42 \pm 19$ & $57 \pm 18$ \\
\hline Control & $8 \pm 3$ & $34 \pm 14$ & $45 \pm 15$ & $58 \pm 15$ \\
\hline \multicolumn{5}{|c|}{$\mathrm{CPP}(\mathrm{mm} \mathrm{Hg})$} \\
\hline ECMO & $66 \pm 19$ & $48 \pm 6$ & $30 \pm 4$ & $19 \pm 3$ \\
\hline Control & $79 \pm 15$ & $48 \pm 3$ & $33 \pm 4$ & $20 \pm 5$ \\
\hline \multicolumn{5}{|l|}{$\mathrm{pH}$} \\
\hline ECMO & $7.36 \pm 0.06$ & $7.37 \pm 0.05$ & $7.38 \pm 0.07$ & $7.37 \pm 0.07$ \\
\hline Control & $7.37 \pm 0.03$ & $7.35 \pm 0.03$ & $7.34 \pm 0.03$ & $7.33 \pm 0.03$ \\
\hline \multicolumn{5}{|c|}{$\mathrm{PaCO}_{2}(\mathrm{kPa})$} \\
\hline ECMO & $4.5 \pm 0.13$ & $4.5 \pm 0.27$ & $4.4 \pm 0.40$ & $4.5 \pm 0.40$ \\
\hline Control & $4.4 \pm 0.40$ & $4.5 \pm 0.27$ & $4.5 \pm 0.27$ & $4.4 \pm 0.27$ \\
\hline \multicolumn{5}{|l|}{$\mathrm{PaO}_{2}(\mathrm{kPa})$} \\
\hline ECMO & $16.3 \pm 4.8$ & $19.0 \pm 4.8 \dagger$ & $18.3 \pm 4.0 \dagger$ & $18.3 \pm 4.0 \dagger$ \\
\hline Control & $14.3 \pm 2.8$ & $13.8 \pm 2.8$ & $13.8 \pm 3.6$ & $13.8 \pm 3.6$ \\
\hline \multicolumn{5}{|l|}{$\mathrm{SaO}_{2}$} \\
\hline ECMO & $0.94 \pm 0.06$ & $0.97 \pm 0.03$ & $0.97 \pm 0.03$ & $0.96 \pm 0.03$ \\
\hline Control & $0.94 \pm 0.05$ & $0.94 \pm 0.04$ & $0.93 \pm 0.04$ & $0.93 \pm 0.04$ \\
\hline
\end{tabular}

*ECMO, $n=7$; control, $n=7$. Values displayed as mean $\pm \mathrm{SD} . \mathrm{SaO}_{2}$, arterial oxygen saturation.

$\dagger p<0.05$ ECMO compared with control.

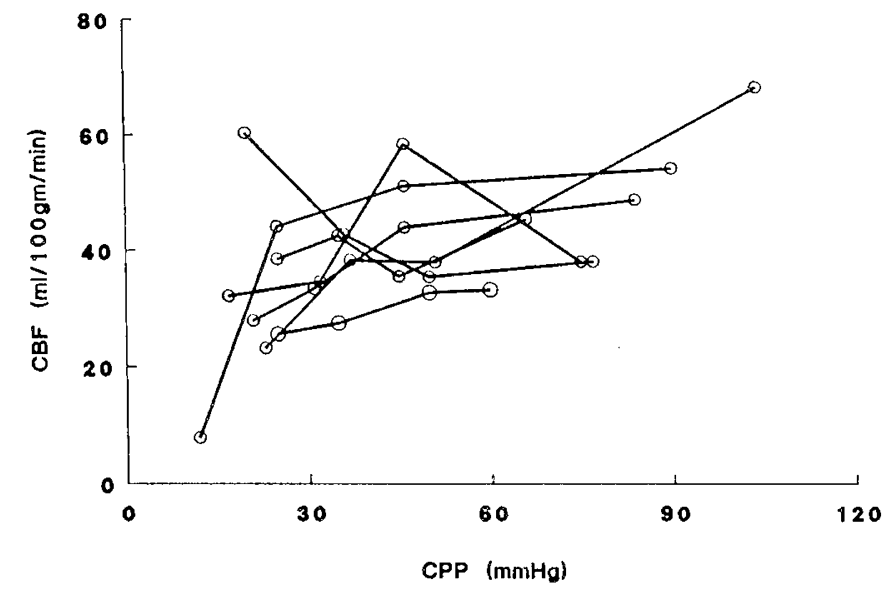

Fig. 1. Data from individual control animals $(n=7)$, depicted as changes in CBF in relationship to CPP.

CPP of 39-25 and $<25 \mathrm{~mm} \mathrm{Hg}(p<0.005)$. Right and left cerebral hemisphere flows of the ECMO animals were lower than those of the controls at CPP of $39-25$ and $<25 \mathrm{~mm} \mathrm{Hg}(p<$ $0.03)$. Only the right hemisphere flows in the control animals decreased from baseline at a CPP of $<25 \mathrm{~mm} \mathrm{Hg}(p=0.03)$ (Table 2).

Regional flow changes over CPP in both ECMO and control animals are shown in Table 2. The CBF changes in ECMO animals in all regions were the same except for the brainstem, where CBF decreased at CPP of 55-40, 39-25, and $<25 \mathrm{~mm} \mathrm{Hg}$ $(p<0.01)$. CBF differences between the ECMO and control animals in all regions were noted at CPP of 39-25 and $<25 \mathrm{~mm}$ $\mathrm{Hg}(p<0.01)$. Brainstem and posterior middle cerebral artery flows in control animals decreased at a CPP of $<25 \mathrm{~mm} \mathrm{Hg}(p$ $<0.05$ ). Caudate flow decreased at CPP of $39-25$ and $<25 \mathrm{~mm}$ $\mathrm{Hg}(p=0.003)$, whereas cerebellum, middle cerebral artery,

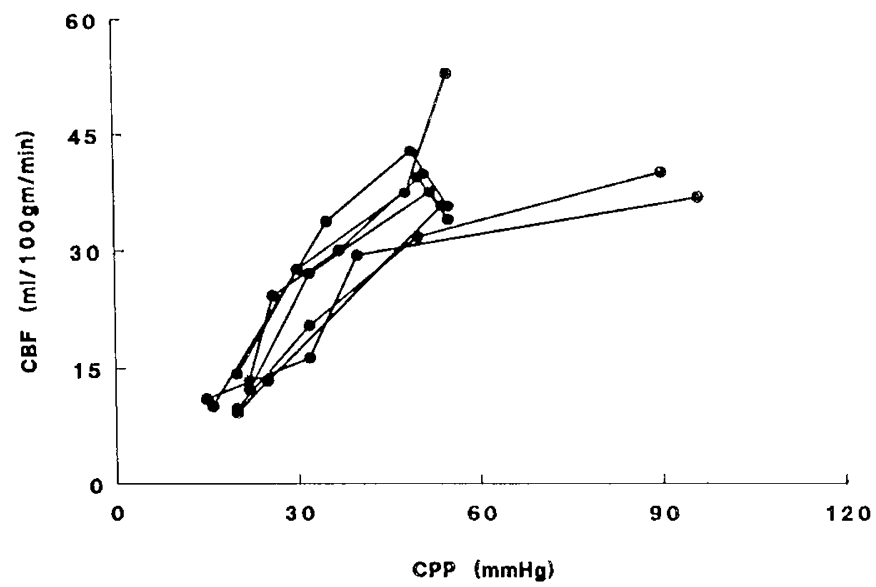

Fig. 2. Data from individual ECMO animals $(n=7)$, depicted as changes in $\mathrm{CBF}$ in relationship to CPP.

posterior cerebral artery, and anterior cerebral artery did not change from baseline at any CPP in the control animals.

\section{DISCUSSION}

Our data show that cerebral autoregulation is altered during venoarterial ECMO in healthy newborn lambs and that at the point of loss of cerebral autoregulation $\mathrm{CMRO}_{2}$ is also decreased. Our data also show right-left CBF differences at the point of loss of cerebral autoregulation (CPP 39-25 in ECMO animals, CPP $<25 \mathrm{~mm} \mathrm{Hg}$ in the control animals). This finding suggests that vessel ligation is an added risk for cerebral injury when $\mathrm{CBF}$ is disrupted.

The significance of the findings in this study is that our model is one of normothermic partial CPB, allowing evaluation of the effect of bypass alone on cerebral autoregulation, without the confounding factors of hypothermia and acid-base blood gas 
Table 2. Regional CBF (mL/100 g/min) for ECMO and control animals as cerebral perfusion pressure was decreased*

\begin{tabular}{|c|c|c|c|c|}
\hline & Baseline & CPP $55-40 \mathrm{~mm} \mathrm{Hg}$ & CPP $39-25 \mathrm{~mm} \mathrm{Hg}$ & $\mathrm{CPP}<25 \mathrm{~mm} \mathrm{Hg}$ \\
\hline \multicolumn{5}{|l|}{$\operatorname{ECMO}(n=7)$} \\
\hline Total cerebrum & $39 \pm 7$ & $35 \pm 5$ & $23 \pm 7 \dagger+$ & $11 \pm 2+末$ \\
\hline Right hemisphere & $38 \pm 6$ & $33 \pm 6$ & $15 \pm 12 \dagger+\S$ & $3 \pm 3+ \pm \S$ \\
\hline Left hemisphere & $42 \pm 7$ & $37 \pm 4$ & $32 \pm 4 \dagger \ddagger$ & $21 \pm 2 \dagger t$ \\
\hline Brainstem & $50 \pm 8$ & $44 \pm 4 \dagger$ & $33 \pm 6+t$ & $18 \pm 3+7$ \\
\hline Caudate & $47 \pm 5$ & $40 \pm 8$ & $25 \pm 10+t$ & $17 \pm 13+t$ \\
\hline Cerebellum & $65 \pm 9$ & $58 \pm 14$ & $39 \pm 15+t$ & $16 \pm 3+t$ \\
\hline $\mathrm{MCA}$ & $41 \pm 8$ & $42 \pm 9$ & $25 \pm 9+t$ & $13 \pm 1+t$ \\
\hline $\mathrm{ACA}$ & $38 \pm 7$ & $33 \pm 6$ & $25 \pm 10+\$$ & $12 \pm 5+t$ \\
\hline PCA & $37 \pm 6$ & $33 \pm 2$ & $23 \pm 9+t$ & $9 \pm 2+7$ \\
\hline PMCA & $41 \pm 9$ & $36 \pm 5$ & $21 \pm 10+\$$ & $10 \pm 4 t+$ \\
\hline \multicolumn{5}{|l|}{ Control $(n=7)$} \\
\hline Total cerebrum & $48 \pm 10$ & $42 \pm 5$ & $36 \pm 7$ & $27 \pm 2 \dagger$ \\
\hline Right hemisphere & $43 \pm 9$ & $40 \pm 9$ & $34 \pm 7$ & $24 \pm 18 \dagger$ \\
\hline Left hemisphere & $50 \pm 14$ & $44 \pm 10$ & $41 \pm 7$ & $34 \pm 15$ \\
\hline Brainstem & $51 \pm 9$ & $52 \pm 12$ & $48 \pm 9$ & $36 \pm 15 \uparrow$ \\
\hline Caudate & $61 \pm 12$ & $51 \pm 18$ & $41 \pm 6+$ & $31 \pm 14 \dagger$ \\
\hline Cerebellum & $71 \pm 11$ & $67 \pm 14$ & $62 \pm 10$ & $46 \pm 28$ \\
\hline $\mathrm{MCA}$ & $47 \pm 9$ & $49 \pm 15$ & $46 \pm 13$ & $36 \pm 23$ \\
\hline $\mathrm{ACA}$ & $42 \pm 11$ & $41 \pm 7$ & $42 \pm 11$ & $37 \pm 34$ \\
\hline PCA & $46 \pm 16$ & $60 \pm 44$ & $60 \pm 60$ & $44 \pm 43$ \\
\hline PMCA & $54 \pm 16$ & $45 \pm 13$ & $38 \pm 8$ & $31 \pm 23 \dagger$ \\
\hline
\end{tabular}

* Values displayed as mean \pm SD. MCA, middle cerebral artery; ACA, anterior cerebral artery; PCA, posterior cerebral artery; PMCA, posteriomiddle artery watershed area.

$\dagger p<0.03$ compared with baseline.

$\ddagger p<0.03$ comparing ECMO with control.

$\S p<0.005$ comparing right hemisphere with left hemisphere.

Table 3. Cerebral metabolic measurements in ECMO and control animals as cerebral perfusion pressure was decreased*

\begin{tabular}{lcccc}
\hline & Baseline & CPP $55-40 \mathrm{~mm} \mathrm{Hg}$ & CPP 39-25 mm Hg & $\mathrm{CPP}<25 \mathrm{~mm} \mathrm{Hg}$ \\
\hline $\mathrm{CMRO}_{2}(\mathrm{~mL} / 100 \mathrm{~g} / \mathrm{min})$ & & & & \\
ECMO & $3.9 \pm 1.1$ & $3.7 \pm 0.8$ & $2.3 \pm 0.9 \dagger \ddagger$ & $1.5 \pm 0.9 \dagger \ddagger$ \\
Control & $4.2 \pm 1.1$ & $4.3 \pm 1.2$ & & $3.2 \pm 1.3 \ddagger$ \\
E & & & $0.65 \pm 0.20$ & $0.70 \pm 0.15$ \\
ECMO & $0.55 \pm 0.11$ & $0.65 \pm 0.14$ & $0.67 \pm 0.14$ & $0.75 \pm 0.14 \ddagger$ \\
Control & $0.54 \pm 0.09$ & $0.62 \pm 0.12$ & $3.4 \pm 1.1 \dagger \neq$ & $2.0 \pm 0.8+\ddagger$ \\
OT (mL/100 g/min) & & & $6.2 \pm 1.4$ & $4.8 \pm 2.8 \ddagger$ \\
ECMO & $6.4 \pm 1.3 \dagger$ & $5.8 \pm 0.8 \dagger$ & $6.9 \pm 0.7$ & \\
Control & $8.0 \pm 2.5$ & & \\
\hline
\end{tabular}

* ECMO, $n=7$; control, $n=7$. Values displayed as mean $\pm \mathrm{SD}$.

$\dagger p<0.03$, ECMO compared with control.

$\ddagger p<0.04$ compared with baseline.

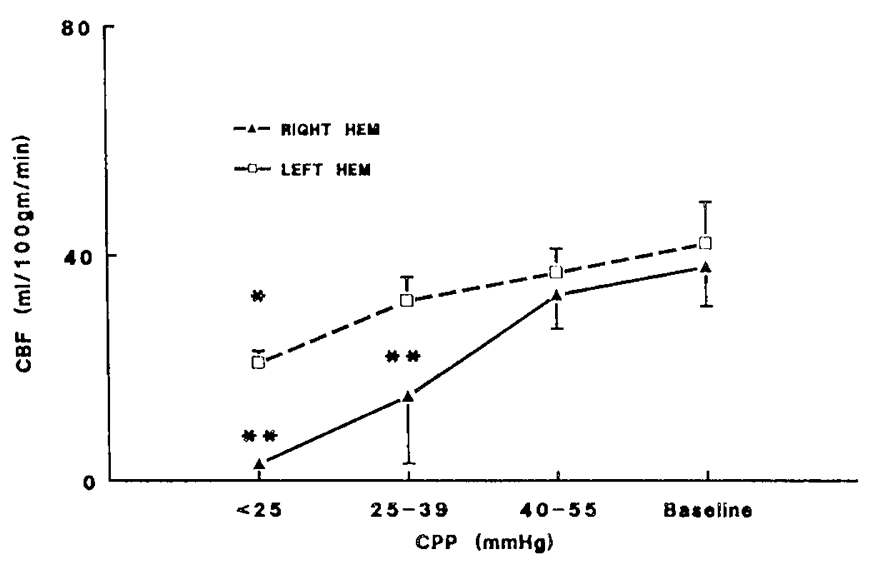

Fig. 3. Right and left hemisphere (HEM) CBF changes over the four CPP ranges for ECMO animals $(n=7)$. Data presented as mean \pm SD. ${ }^{*}, p<0.001$ compared with baseline values for each hemisphere; ${ }^{* *}, p<$ 0.005 comparing right with left hemisphere flows. management seen in CPB studies. Results of human studies of the effect of CPB on cerebral autoregulation are conflicting, with some authors showing altered cerebral autoregulation $(6,7)$ and others showing no effect $(8,9)$. Besides differences in hypothermia, acid-base management, and other parameters such as anesthesia and membrane lung versus bubble oxygenators, all clinical studies have been limited in their ability to critically assess cerebral autoregulation because of the narrow range of blood pressures and CPP that can be studied (9). Review of most studies shows that the ranges of CPP or MAP are within the normal autoregulatory range. To demonstrate a shift in the autoregulatory threshold, CPP must be systematically varied over a wide range, which is difficult in clinical settings. The present study, through the use of an animal model that eliminates hypothermia and acid-base management as confounding factors, has clearly shown that partial normothermic bypass alters cerebral autoregulation. The lower limit of autoregulation in the ECMO animals was at a CPP of $39-25 \mathrm{~mm} \mathrm{Hg}$, whereas control animals autoregulated to a CPP $<25 \mathrm{~mm} \mathrm{Hg}$. With the decrease in $\mathrm{CBF}$ at the point of loss of autoregulation, OT decreased and $\mathrm{E}$ did not increase to stabilize $\mathrm{CMRO}_{2}$. These alterations in cerebral metabolism could result in cerebral injury if this state persists. 
Autoregulation of the cerebral circulation was first observed by Fog in 1930 (15), with the concept of blood flow constancy during perfusion pressure changes fully established by Lassen in 1959 (16). The precise mechanism of autoregulation remains obscure, but two mechanisms have been suggested: Myogenic and metabolic (1-3). According to the myogenic hypothesis, the arterioles respond to intravascular pressure as a stimulus, with pressure elevation causing constriction. It could be postulated that the effect of altered pulsatile blood flow caused by the ECMO pump could effect cerebral autoregulation through the myogenic response. The effect of nonpulsatile flow on the brain has been of concern in CPB $(17,18)$. Tranmer et al. (18) compared pulsatile and nonpulsatile bypass in dogs with acute focal cerebral ischemia and found that pulsatile flow increased CBF significantly over nonpulsatile flow. In the present study, only partial $\mathrm{CPB}$ was used. Although systemic pulse pressures were not significantly changed by the ECMO flows used in this study, Doppler flow studies in infants on ECMO similar to those used in this study have shown that the anterior cerebral artery pulse pressures are dramatically altered (19). Thus, the effect of ECMO on the myogenic mechanisms of cerebral autoregulation could be responsible for the alteration seen in this study. This could be tested by studying a form of ECMO that allows normal cardiac output from the left ventricle, such as venovenous ECMO.

The metabolic hypothesis for cerebral autoregulation states that changes in micro-environment alter the vasomotor response, with vasoactive substances such as adenosine being implicated as mediators of the response (1-3). It is known that vasoactive mediators such as complement and prostaglandins are activated by exposure of blood to artificial surfaces in ECMO and CPB $(20,21)$. It could be postulated that an altered relationship of these vasoactive agents, i.e. increased production caused by contact with artificial surfaces, or an alteration of their metabolism could play a role in the alterations of cerebral autoregulation, but these hypotheses were not tested in this study. The effect of other potentially toxic substances such as plasticizers, which are known to come off the ECMO circuit tubing in significant amounts (22), on the brain is unknown but should be considered when addressing possible mechanisms of altered cerebral reactivity.

Altered autoregulation has been implicated in cerebral injury by making the cerebral microvasculature vulnerable to systemic blood pressure changes $(23,24)$. Although our findings of altered cerebral autoregulation are in healthy newborn lambs and may not be necessarily extrapolated to the sick, newborn human infant, they do raise concern for the effect of the ECMO procedure itself on cerebral autoregulation and could implicate the ECMO procedure as a risk factor for cerebral injury, which helps to explain the increased risk for intracranial abnormalities noted in the ECMO population (11). In the present study, $\mathrm{CMRO}_{2}$ was significantly reduced when autoregulation was lost, indicating the potential for cerebral injury. Clinically, during the first hours of ECMO therapy, significant cardiovascular changes can occur, including hypertension and/or hypotension. Each of these events can result in significant changes in CPP and in the face of loss of cerebral autoregulation could cause either cerebral ischemia or hyperemia. Sell et al. (25) have reported a significant relationship between hypertension while on ECMO and the increased incidence of intracranial hemorrhage seen in their population. Infants placed on ECMO are also recovering from severe hypoxia and/or asphyxia, both of which are known to alter cerebral autoregulation $(1,3,5)$.

Although right-sided cerebral lesions are not consistently found in the ECMO population, Schumacher et al. (26) noted a predominance of right-sided lesions in infants who were placed on ECMO during cardiopulmonary resuscitation (11). Increased vulnerability of the right side of the brain to changes in $\mathrm{CBF}$ with vessel ligation, combined with the added risk for cerebral ischemia from altered cerebral autoregulation secondary to the
ECMO procedure, as seen in our study, may explain the findings of Schumacher et al.

The limitations of our study are 3-fold: the acute nature of the preparation, the use of the newborn lamb, and the limited evaluation of the autoregulatory curve. Because only $1 \mathrm{~h}$ of ECMO exposure was used in this preparation, we did not address the long-term effect of ECMO on cerebral autoregulation; most infants are on ECMO for 5-6 d (10). It could be postulated that only the first few hours on ECMO are of concern because of the significant cardiovascular changes that occur during this time period. This would be supported if the etiology of these changes is solely due to activation of vasoactive mediators. Unfortunately, other possible etiologies, such as toxic substances (plasticizers), must be considered, and in such cases the exposure can be for days. Under these circumstances, the alterations in cerebral autoregulation could continue with time on ECMO.

The human circle of Willis receives blood from the internal carotid artery, whereas the circle of Willis in the lamb is supplied from the external carotid through a rete mirabile with no contribution from a vertebrobasilar connection $(27,28)$. If altered pulsatile flow was thought to be a mechanism in the changes seen in autoregulation, presence of the rete mirabile could raise theoretical concerns as to whether pulse pressure would be dampened with pulse pressure changes not being transmitted to the brain in this model. These concerns have been disproved by studies in the goat, which has the same vascular anatomy as the sheep, that have shown that pressure is pulsatile in the middle cerebral artery (29). Studies in our laboratory using transcranial Doppler techniques have shown normal pulse pressures in the small cerebral arteries of the lamb (30). Another concern is the well-developed vertebral-carotid anastomosis via the occipital artery in the lamb, which could mask the right-left CBF changes. Because right-left CBF changes were found in our study, this risk may be greater in the human, in whom this anastomosis is not as developed (28). The other anatomical concern in the lamb is the presence of a brachycephalic trunk off the aortic arch, from which the carotid arteries arise (31). Previous studies in our laboratory evaluating three simultaneous reference sites (left and right brachial arteries and lingual arteries) have shown that equal distribution of flow occurs with the ECMO arterial catheter in place, without evidence of obstruction (12).

Cerebral autoregulation is evaluated by changing CPP over a wide range. This can be evaluated in one of three ways: increasing or decreasing systemic pressure, increasing ICP, or elevating cerebral venous pressure $(32,33)$. Because of the mechanism on the ECMO system, called the "venous return monitor," which stops the ECMO pump if venous return is decreased (which would occur with graded hemorrhage), one cannot use the method of lowering systemic pressure for determining cerebral autoregulation. Therefore, the method used in this study was that of increasing ICP and thus lowering CPP, a method used extensively in physiologic research $(32-35)$. The limitations of this method are that only the lower end of the autoregulatory curve can be determined, and thus we have not addressed the upper limits of autoregulation in this model.

In summary, we have shown that normothermic partial $\mathrm{CPB}$ or ECMO significantly alters cerebral autoregulation in the healthy newborn lamb and that carotid ligation with ECMO may be an important risk factor in right-sided cerebral ischemia when $\mathrm{CBF}$ autoregulation is lost. Although mechanisms for these findings are not understood, these findings do indicate that significant cardiovascular alterations, such as severe hypotension, could result in $\mathrm{CBF}$ alterations and, if prolonged, could result in cerebral injury. Although it is difficult to extrapolate these findings in the healthy, newborn lamb to the sick, human infant, one should consider that cerebral autoregulation alterations secondary to the ECMO procedure could be a risk factor for the development of cerebral injury in the sick newborn placed on ECMO. 


\section{REFERENCES}

1. Lassen NA 1964 Autoregulation of cerebral blood flow. Circ Res 14(suppl 1):1201-1-204

2. Paulson OB, Waldeman G, Schmidt JF, Strandgaard S 1989 Cerebral circulation under normal and pathologic conditions. Am J Cardiol 63:2C-5C

3. Strandgaard S, Paulson OB 1984 Cerebral autoregulation. Stroke 15:413-415

4. Papile LA, Rudolph AM, Heymann MA 1985 Autoregulation of cerebral blood flow in the preterm fetal lamb. Pediatr Res 19:159-161

5. Tweed A, Cote J, Lou H, Gregory G, Wade J 1986 Impairment of cerebral blood flow autoregulation in the newborn lamb by hypoxia. Pediatr Res 20:516-519

6. Greeley WJ, Ungerleider RM, Smith R, Reves JG 1989 The effects of deep hypothermic cardiopulmonary bypass and total circulatory arrest on cerebral blood flow in infants and children. J Thorac Cardiovasc Surg 97:737-745

7. Johnsson P, Messeter K, Ryding E, Nordstrom L, Stahl E 1987 Cerebral blood flow and autoregulation during hypothermic cardiopulmonary bypass. Ann Thorac Surg 43:386-390

8. Govier AV, Reves JG, McKay RD, Karp RB, Zorn GL, Morawetz RB, Smith LR, Adams MAM, Freeman AM 1984 Factors and their influence on regional cerebral blood flow during nonpulsatile cardiopulmonary bypass. Ann Thorac Surg 38:592-600

9. Thompson IR 1989 The influence of cardiopulmonary bypass on cerebral physiology and function. In: Tinker $\mathrm{JH}$ (ed) Cardiopulmonary Bypass: Current Concepts and Controversies. WB Saunders, Philadelphia, pp 21-39

10. Stolar CJH, Snedecor SM, Bartlett RH 1991 Extracorporeal membrane oxygenation and neonatal respiratory failure: experience from the extracorporeal life support organization. J Pediatr Surg 26:563-571

11. Taylor GA, Short BL, Fitz CR 1989 Imaging of cerebrovascular injury in infants treated with extracorporeal membrane oxygenation. $J$ Pediatr 114:635-639

12. Short BL, Walker LK, Gleason CA, Jones MD, Traystman RJ 1990 Effect of extracorporeal membrane oxygenation on cerebral blood flow and cerebral oxygen metabolism in newborn sheep. Pediatr Res 28:50-53

13. Bradbury MWB, Crowder J, Desal S, Reynolds JM, Reynolds M, Saunders NR 1972 Electrolyte and water in the brain and cerebrospinal fluid of the foetal sheep and guinea-pig. J Physiol (Lond) 227:591-610

14. Heymann MA, Payne BD, Hoffman JIE, Rudolph AM 1979 Blood flow measurements with radionuclide-labeled particles. Prog Cardiovasc Dis 20:55-79

15. Fog M 1937 Cerebral circulation. The reaction of the pial arteries to a fall in blood pressure. Arch Neurol Psych 37:351-364

16. Lassen NA 1959 Cerebral blood flow and oxygen consumption in man. Physiol Rev 39:183-238

17. Edmonds LH 1982 Pulseless cardiopulmonary bypass. J Thorac Cardiovasc Surg 84:800-804

18. Tranmer BI, Gross CE, Kindt GW, Adey GR 1986 Pulsatile versus nonpulsatile blood flow in the treatment of acute cerebral ischemia. Neurosurgery 19:724731

19. Taylor GA, Martin BL, Short BL 1989 Cardiac determinants of cerebral blood flow during extracorporeal membrane oxygenation. Invest Radiol 24:511516

20. Greeley WJ, Bushman GA, Kong DL, Oldham HN, Peterson MB 1988 Effects of CPB on eicosanoid metabolism during pediatric cardiovascular surgery. $J$ Thorac Cardiovasc Surg 95:842-849

21. Chenoweth DE 1987 Complement activation in extracorporeal circuits. In: Leonard EF, Turitto VT, Vroman L (eds) Blood in Contact with Natural and Artificial Surfaces. NY Academy of Science, New York, pp 306-313

22. Schneider B, Schena J, Truog R, Jacobson M, Kevy S 1989 Exposure to di(2ethylhexyl)phthalate in infants receiving extracorporeal membrane oxygenation. N Engl J Med 320:1563

23. Lou HC, Lassen NA, Friis-Hansen B 1979 Impaired autoregulation of cerebral blood flow in the distressed newborn infant. J Pediatr 94:118-121

24. Pape KE 1989 Etiology and pathogenesis of intraventricular hemorrhage in newborns. Pediatrics 84:382-385

25. Sell LL, Cullen ML, Lerner GR, Whittlesey GC, Shanley CJ, Klein MD 1987 Hypertension during extracorporeal membrane oxygenation: cause, effect, and management. Surgery 102:724-730

26. Schumacher RE, Barks JDE, Johnston MV, Donn SM, Scher MX, Roloff DW, Bartlett RH 1988 Right-sided lesions in infants following extracorporeal membrane oxygenation. Pediatrics 82:155-161

27. Daniel PM, Dawes JDK, Prichard MM 1953 Studies of the carotid rete and its associated arteries. Philos Trans R Soc Lond [Biol] 237:173-208

28. Baldwin BA, Bell FR 1963 The anatomy of the cerebral circulation of the sheep and ox. The dynamic distribution of the blood supplied by the carotid and vertebral arteries to cranial region. J Anat 97:203-215

29. Edelman BA, Epstein P, Cherniack NS, Fishman AP 1972 Control of cerebral flood flow in the goat: role of the carotid rete. Am J Physiol 223:615-619

30. Taylor GA, Short BL, Walker LK, Traystman RJ 1990 Quantification of intracranial blood flow with duplex Doppler and color flow imaging. Radiology 176:231-236

31. Hecker JF 1983 Anatomy. In: Hecker JF (ed) The Sheep as an Experimental Animal. Academic Press, New York, pp 14-32

32. Borel CO, Backofen JE, Koehler RC, Jones MC, Traystman RJ 1987 Cerebral blood flow autoregulation during hypertension in hypoxic animals. Am J Physiol 253: H1342-H1348

33. McPherson RW, Koehler RC, Traystman RJ 1988 Effect of jugular venous pressure on cerebral autoregulation in dogs. Am J Physiol 255:H1516-H1524

34. Haggendal E, Lofgren J, Nilsson NJ, Zwetnow NN 1970 Effects of varied cerebrospinal fluid pressure on cerebral blood flow in dogs. Acta Physiol Scand 79:262-271

35. Kjallquist A, Siesjo BK, Zwetnow N 1969 Effects of increased intracranial pressure on cerebral blood flow and cerebral venous $\mathrm{PO}_{2}, \mathrm{PCO}_{2}, \mathrm{pH}$, lactate, and pyruvate in dogs. Acta Physiol Scand 75:267-275 